\title{
¿REPRESENTAR O SIMULAR? \\ ESA ES LA PREGUNTA \\ LOS LÍMITES DE LA REPRESENTACIÓN
}

\begin{abstract}
Virginia Guarinos
Profesora titular de Narrativa audiovisual y del espectáculo. Universidad de Sevilla.
\end{abstract}

\section{Resumen}

La aparición de nuevos modos y medios de expresión y comunicación del último siglo han implicado una nueva manera de afrontar las formas de representación. Todas ellas, vinculadas al universo del ocio desde el punto de vista del consumidor y del negocio desde la visión del productor, suponen unas maneras de representar la realidad muchas veces poco relacionadas con la representación en el sentido de actuación y muy vinculadas al fingimiento, a la simulación cuando no a la mentira. La revisión de los términos y/o de los conceptos nos llevará a reflexionar sobre el factor humano y sus nuevas relaciones sociales con respecto al teatro y sobre el teatro en relación a las actuales maneras de reinventar roles de un modo no profesional.

\section{Palabras clave}

Teatro - Internet - Videojuegos - Nuevas tecnologías - Representación - Simulación 


\section{Abstract}

The appearance of new ways and means of expression and communication from last century has implied a new way to confront the representation forms. All of them, tie to the universe of the leisure from the point of view of the consumer and the business from vision of the producer, suppose ways to represent the reality often little related to representation like theatre and very related to simulation when not to lie. The revision of the words and/or the concepts took to us to reflect on the human factor and its new social relations in relation with the theatre and on the theatre in relation to the present ways to recreate rolls on a nonprofessional way.

\section{Key words}

Theatre - Internet - Videogames - New Technologies - Representation - Simulation

\section{Introducción}

La teoría del teatro, tan consolidada desde hace años, está siendo sometida a envites desde otros medios y modos de representación no porque dicha teoría deba ser revisada como tal de forma absoluta sino porque otras prácticas sociales de comunicación y ocio han venido a complicar nuestra asentada idea de lo teatral, lo dramático, y con ella la representación, la simulación... El uso de juegos dramáticos con distintos fines terapéuticos y didácticos ha dejado de ser algo original y diferente al teatro en comparación con los nuevos juegos de ordenador, juegos de simulación, y las posibilidades de fingimiento y “teatralización” que permite el desdoble de la personalidad a través de avatares en foros, chats y juegos on line en Internet.

\section{Objetivos}

Podríamos partir de la idea de que nada hay nuevo bajo el sol, recordemos que ya Goffman lo dijo a propósito de los convencionalismo sociales, la interpretación social, y el empleo de diversos registros de comportamiento en función de los ambientes, los interlocutores e intenciones que 
tengamos en nuestro actividad comunicativa diaria así lo confirman. No obstante, la complejidad de estos nuevos formatos, medios y modos de ocio, merecen una reflexión sobre ello. Ese es el objetivo de este artículo repensar las diferencias entre simulación e interpretación al mismo tiempo que calibrar cuál es la posición del teatro dentro de la virtualidad.

\section{Metodología}

La metodología empleada combinará diversas teorías que intervienen dentro de la complejidad del discurso teatral y de las nuevas tecnologías y sus entornos. Se recurrirá a la Teoría del Teatro así como a la Teoría de la Comunicación, la comunicación no verbal, la Sociología y la Narrativa comparada, centrándose en diversos aspectos de la dramatización, especialmente los referidos a la figura del actor, el espectador y el jugador y usuario de juegos de rol, videojuegos, comunidades virtuales...

\section{Acercamiento al tema}

La dramatización es una técnica que excede al teatro. Ahora bien, la extensión de modos teatralizantes podría llevarnos incluso a una redefinición de teatro a la vista de las muy diversas experiencias que nos encaminan hacia una transmedialidad, a un transvase de técnicas, modos de expresión de un medio hacia otros, una internacionalización, globalización de procedimientos expresivos que ya no son exclusivos de un solo medio, del medio original al que pertenecían o que los desarrolló. La dramatización viene siendo desde antiguo incluso una medida terapéutica (escenoterapia) $^{1}$ o instrumento didáctico, especialmente las dramatizaciones en la escuela, sobre lo que se halla amplísima bibliografía. E incluso de la simulación se ha construido toda una metodología de investigación en Sociología.

Pero dramatizar, simular, interpretar, aunque son términos que usamos con intenciones sinónimas, no hacen referencia a la misma actividad. Entre dramatizar/representar/interpretar y

\footnotetext{
${ }^{1}$ Véase el libro de Víctor Cabré (2002) de este mismo título (Barcelona, Paidós).
} 
simular existe una barrera que puede llevar a diferenciar la realidad de la ficción. Como síntoma de nuestra postmodernidad ese borrado de la frontera ficcional se encuentra en muchos textos ficcionales, desde el propio informativo a series televisivas (series de investigación forense con retórica de documental, por ejemplo). La telerrealidad que comenzara tímidamente con los formatos docudramáticos se extiende ya a documentales dramatizados, y por tanto ficcionalizados, y a series que pretenden ser científicas y objetivas en sus modos de presentar los casos forenses. La realidad reconstruida es algo tan viejo como el uso de forma documental en cine de ficción (Ciudadano Kane, de O. Welles 1941, o Zelig, de W.Allen 1983, son ejemplos clásicos). Pero el pacto espectatorial del que habla Bettetini ${ }^{2}$ en estos medios funciona a pleno rendimiento. El espectador es consciente de lo que está viendo y asume pactar en realidad o en ficción, conoce las claves porque los textos están enmarcados sintagmática y paradigmáticamente en lo que debe ser interpretado como realidad y como ficción.

\section{Representación y simulación desde la}

\section{Teoría del teatro}

Existen hoy otras maneras de dramatizar, que no se corresponden con interpretar sino con simular. Los videojuegos, la realidad virtual, los juegos de rol presenciales o virtuales han abierto un abanico de posibilidades de interpretación y/o reinvención de nosotros mismos que obliga a una redefinición de lo teatral vinculado o no a las nuevas tecnologías.

Según el Diccionario de la Real Academia Española de la Lengua, ${ }^{3}$ simulación es "la acción de simular”. Simular es “representar algo, fingiendo o imitando que lo es”. Ahora bien, ese representar es distinto al de la representación en sentido más extendido. Representar, en su cuarta acepción, es "recitar o ejecutar en público una obra dramática”, y en su quinta acepción es

\footnotetext{
${ }^{2}$ La conversación audiovisual, Madrid, Cátedra, 1986.

${ }^{3}$ Véase en la versión on line de la 22 edición del diccionario, 2001: http://buscon.rae.es/draeI/ (12/II/2008).
} 
"interpretar un papel de una obra dramática”. Dramatizar, por su parte, es "dar forma y condiciones dramáticas”, y como segunda acepción, “exagerar con apariencias dramáticas o afectadas”. La dramatización es "la acción y efecto de dramatizar”. Todos estos términos están evidentemente vinculados a dos elementos más: el de la obra dramática y del público. Por el contrario imitar o fingir, palabras que se encuentran dentro del concepto de simular, se relacionan en sus definiciones con: mentir ("fingir, aparentar"), fingir (“dar a entender lo que no es cierto”, o como tercera acepción "simular, aparentar”), aparentar ("manifestar o dar a entender lo que no es o no hay”). Simular es fingir y en el fingimiento ya no hay ni obras dramáticas ni público.

Los diccionarios especializados vienen a reforzar la diferencia entre ambos conceptos e incluyen la referencia al teatro y la teatralización. En el de Portillo y Casado (1992), dramatizar es sinónimo de teatralizar y no aparece el término “simulación”. En el mismo volumen interpretar es “hacerse cargo de un papel en una obra, dándole vida en escena; es, por tanto, sinónimo de actuar” (1992: 96) y actuar y actuación son respectivamente "trabajar como actor en una obra”, e “interpretación, actividad de un actor sobre el escenario” (1992: 9). En el mismo sentido Pavis (1983) define dramatización como teatralización y tampoco hace aparecer la palabra simulación. Teatralización es para Pavis el resultado de teatralizar, y a su vez teatralizar "un acontecimiento o un texto es interpretarlo escénicamente utilizando escenarios y actores para instalar la situación” (1983: 471). El elemento visual de la escena y la puesta en situación de los discursos son las marcas de la teatralización. Se nos presentan, por tanto, diferencias entre la representación teatral y "las otras”: la existencia de un mensaje que transmitir por esa vía (el texto dramático) y de un público al que enviar dicho mensaje. Además, a través de la actuación entra en conflicto otro elemento, el del actor. Pavis dice sobre la interpretación que "el actor no asume un rol de usuario y transformador del mensaje a transmitir” (1983: 275) sino que cumple con la actuación regida y prevista por el director.

Todas estas definiciones marcan mucho el texto cerrado que se interpreta y el espacio donde se hace, aunque existe otro elemento, ya sugerido, que marca la recepción del conjunto de la puesta en escena: el espectador. Unido indisolublemente a él está el contrato comunicativo, el pacto ficcional que el espectador asume en ese espacio donde sabe que lo que va a ver es teatro, posee las claves. Nunca sucederá en un espacio convencional o no de teatro, lo que acontece cuando encontramos a un grupo de personas disfrazadas de vampiros por la calle, hecho ante el que 
podemos pensar que se dirigen a una fiesta de disfraces, aunque raramente imaginamos que puedan estar jugando a rol.

Si repasamos la Teoría del teatro tradicional, la creación de nuestra propia obra y nuestro propio personaje en los chats, en los juegos por Internet, donde mayor libertad creativa tenemos cubiertos por la distancia y el anonimato, observaremos la diferencia entre interpretar y simular también es grande. Con respecto al propio texto teatral, sus espacios, sus objetos, sus contenidos, como afirma Anne Ubersfeld (1989: 183) “el mensaje que esta palabra ofrece (la teatral) no es referencial o, más exactamente, sólo remite al referente escénico. Sólo dice lo que está en escena (lo que está o debe estar)”. Dicho mensaje no remite a nada de la experiencia real, luego cuando interpretamos en cualquiera de estos medios acerca de las experiencias reales, más que interpretar, mentimos. Por otro lado, al margen de la improvisación, que siempre encaja dentro de unos límites que no se exceden, la clausura de un texto dramático es base de trabajo para los propios actores y de decodificación para los espectadores.

En nuestras actividades de chateo o juego el guión no está cerrado, a veces ni siquiera abierto, en tanto que no existe. Carmen Bobes (1987: 191) afirma que "la noción de personaje cambia pragmáticamente por relación al horizonte de expectativas de una cultura y por relación a la competencia de los espectadores... La puesta en escena de obras cuyos personajes no actúan como podía esperarse produce desconcierto en los espectadores”. Es cierto que el teatro contemporáneo se está desmarcando del perfil del personaje tradicional, creando el conflicto que entre los teóricos se llama la crisis del personaje, su deconstrucción, en clara distancia con el uso y abuso que de los personajes dramáticos y construcciones dramáticas hacemos hoy: la representación de uno mismo o construcción de un personaje entre los frikies televisivos es una prueba más de ello. Las teorías psicoanalíticas aplicadas a teatro descubren personajes que se desconocen a sí mismos y que conforme se desarrollan se van conociendo, teorías de Freud y Jung. Pero incluso así, incluso deconstruido, “el actor da cuerpo al personaje -como afirma Abirached (1994: 70)- no se sumerge en él (...) al contrario, le hace emerger aquí y ahora, inscribiéndolo en una imagen material”. La distancia entre el personaje y el mundo real se evidencia por su codificación. También lo afirma Abirached (1994: 73) para el personaje moderno puesto que "actuar se percibe como una conducta del imaginario, que moviliza todas las energías de quien actúan sin procurarles una salida en el mundo real; codificado siempre, exige de quien actúa un mínimo de conciencia que le permita dominar las reglas que se impone; fundador de una verdad que le es propia y sometido a una lógica 
arbitrariamente instaurada y libremente reconocida; provoca un gasto de energía personal y colectiva que no se encamina a la producción de ningún beneficio: en cierta manera, la gratuidad de su ejercicio explica el desdoblamiento de quien actúa, que se ve hacer y sin embargo no tiene ningún problema en ponerse en cuestión a sí mismo en ese otro tiempo y ese otro espacio que sabe radicalmente diferentes a su vida”, desarrollando la definición de Huizinga (1951) en la separación entre juego e interpretación.

Ningún otro teórico como André Helbo ha sabido otorgar al espectador la importancia básica que posee en la transferencia dramática. Para él (1987: 25), “el actante espectador (...) puede ser considerado como un rol cognitivo, y de ese modo, como la instancia que legitima el discurso”, no es un simple observador. Característica de ese observador es no estar marcado, ya que no aparece en lo enunciado, su presencia es silenciosa y vive en la paradoja porque al mismo tiempo observa el hecho de la conducta simulada de los actores sabiendo que la ficción está divorciada de la dimensión de veridicción, y sabiendo que la ilusión se pierde si se desenmascara. En palabras de Helbo (1987: 26), "el espectador interpreta el juego del colectivo escénico, pero al mismo tiempo que se persuade a aceptar un orden de creencia (ilusión), persuade al actor de seguir actuando”. Esta intencionalidad y actuación del espectador teatral, o de cualquier otro espectáculo pactado, se pierde si el espectador no es consciente de la actuación. Por otro lado, la recepción es por naturaleza colectiva en teatro, mientras que en los juegos en línea o los chats la recepción es individual la mayor parte de las veces. Algunas voces, como la de Sito Alba, reivindican una ampliación de la noción de espectador, pero siempre dentro de unos límites si no espectaculares, sí de recepción artística. "La teatralidad - dice Sito Alba (1987: 191)- puede darse fuera del teatro (...) los mimemas pueden surgir en la vida, en la narrativa, en las artes plásticas (...) por lo cual el concepto de público, hemos de ampliarlo”. Pero siempre -a excepción de “en la vida”- se refiere a otros modos de representación más que de teatralidad, nunca al juego o la simulación donde el receptor es un receptor pero no un espectador, en tanto que no es consciente de estar ante un espectáculo para sus ojos, para su lectura matizada, no para el engaño.

A la luz de las últimas teorías, se sigue insistiendo en que en teatro ningún signo puede no significar y además cualquier signo puede ser teatral, ya que no existen signos específicos teatrales, todo dependerá de su sentido y función en el entramado de cada obra concreta y de los demás signos implicados. De ello se deduce que puede haber teatro en cualquier parte y con cualquier elemento; ahora bien, en la recepción entran a formar parte elementos importantes como estimulación, 
comunicación e interpretación, de lo que se deduce también que el espectador debe ser consciente de que es un espectador, debe sentirse estimulado para ello, debe mantener una comunicación teatral y debe tener todas las claves para interpretar lo que está viendo. Toda representación teatral es siempre: fugaz, irrepetible, reproductible, artificial, artística, plurimodal, ficticia y real y, sobre todo, intencional: se dirige a un público con intención comunicativa para transmitirle ideas, emociones... El actor interpreta no como si fuera él (el actor) sino como si fuera el otro, que siempre es un personaje, es decir, un ente de ficción. Pero, como afirma Trancón (2006), el teatro es real porque es tangible, con lo que la virtualidad quedaría fuera de la perspectiva de lo que es teatro. Además, el teatro, así lo afirma el mismo teórico (2006: 358) “en contra de lo que con frecuencia se supone, no es el lugar del exhibicionismo ni del narcisismo, sino todo lo contrario: el lugar en que desaparece el

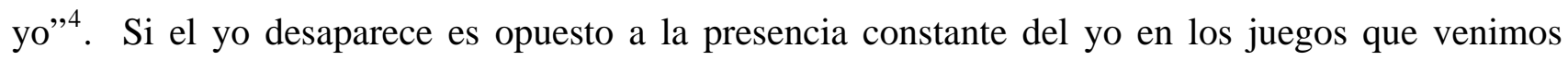
comentando, donde la interferencia entre el ser y el parecer es constante en la simulación. El espectador, por su parte, está condicionado por no poder entrar en la ficción, su separación física del espectáculo, las limitaciones de percepción visual, la convención de no intervenir en la representación de forma voluntaria y tomando la iniciativa, la aceptación de la convención inicial de que todo lo que ve y oye no es verdad aunque sea real, la convención de suplir con imaginación lo que no ve y oye aceptándolo como que ha sucedido, sabe que todo es distinto de lo real de la vida cotidiana. Y gracias a estas convenciones y comportamiento receptivo, el espectador, no se plantea la verdad o falsedad de lo que ve, es lo que llama Siegfried J. Schimidt (1987) la regla F. En los juegos on line, en el chat, el ingenuo espectador puede no saber que es un espectador de un constructo creado para él y no se plantea la verdad o falsedad de lo que ve porque da por sentada la verdad de lo que se le cuenta, justo al revés que el espectador de teatro, que aunque no se lo plantea es siempre consciente de dicha falsedad o no verdad.

\section{Nuevos modos de representación/simulación}

Uno de los modos relacionados con el replanteamiento de representación y simulación es el juego de rol. En sus distintas modalidades de mesa, por ordenador, on line, los juegos de rol se

\footnotetext{
${ }^{4}$ Hay teorías varias para las escuelas de actores y sus procedimientos de trabajo. El actor debe enmascararse y ocultar su yo; el actor no debe emocionarse porque si lo hace puede romper el papel o al menos el espectador no debe notarlo porque “desrealizaría” la ficción; el actor debe demostrar que controla la emoción, la domina... Y muchos teóricos han hablado sobre el actor y su doble (el personaje), a veces con visiones opuestas, Stanislavski, Grotowsky...
} 
asemejan entre sí, pero la que más nos interesa es el juego de rol en vivo. Emparentado con actividades como el cuentacuentos, los juegos dramáticos, las dramatizaciones, padece una mala prensa considerable fomentada por leyendas urbanas y películas que recrean grupos de personas con actitudes psicopáticas. Independientemente de ello, se cuentan por miles los aficionados a dicho modo de ocio y en todo juego de rol hay drama, juego y simulación. Bien es cierto que algunos piensan que el rol debe ayudar a redefinir el teatro mientras otros permanecen en la simulación ${ }^{5}$ sin pretender la existencia de representación, pero lo cierto es que se olvidan de un factor importantísimo que es el público. En un juego de rol en vivo no suele haber público más que los propios intervinientes, que no pueden ser actores y espectadores de los otros actores al mismo tiempo: o forman historia o están fuera de la historia. El jugador efectivamente interpreta un personaje predefinido, hasta ahí bien. Podría decirse que hay interpretación pero dicha interpretación debe ser con intencionalidades comunicativas distintas de la única entre jugador y jugador, sobre todo entre actor/personaje y espectador. Los jugadores de rol no interpretan una historia para enviar un mensaje a terceras personas ajenas al propio juego. Su texto no está cerrado y su representación no se organiza en un espacio recognoscible como dramático, como convencional para esta actividad.

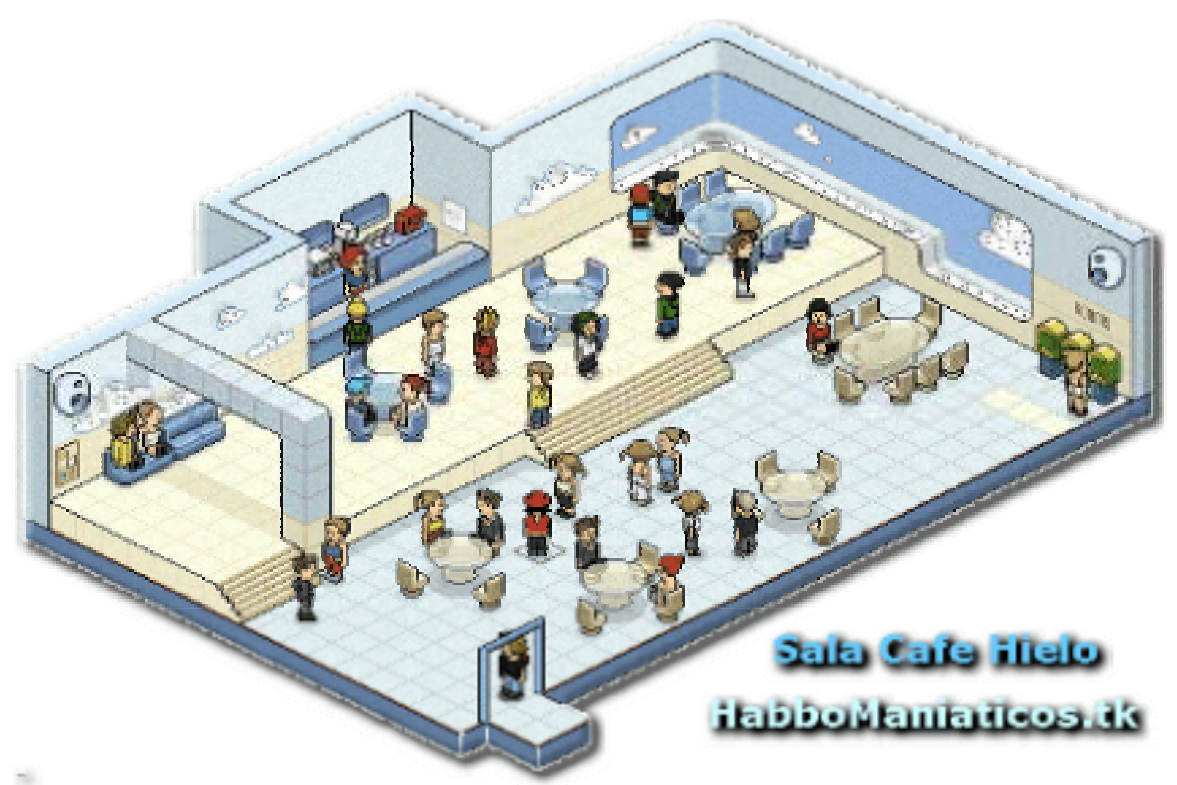

Sala común del juego on line Habbo, donde cada avatar es un internauta.

\footnotetext{
${ }^{5}$ Dentro del propio seno de los amantes del rol existe una separación entre los dramatistas y los simulacionistas (escuela nórdica).
} 
A pesar de ello, el rol posee la posibilidad de lo tangible. Las nuevas formas de ocio han abierto un mundo a nuestro alrededor impensable hace unos años. A diferencia de la realidad física de los jugadores de rol simulando personajes, la inexistencia próxima más que como imágenes generadas en una pantalla es la característica de las comunidades virtuales o juegos de simulación de la vida real por ordenador. Las primeras crean ciudades imaginarias, donde cada individuo elige un avatar y se mueve por esa realidad con él, es su cuerpo, e interactúa con otros avatares. Sin guión previo ni límites, más que las reglas internas de convivencia, así funcionan comunidades para adultos, como Second Life, para niños, como Habbo, hasta sólo para niñas, como Barbiegirls, y algunas generadas por cadenas de televisión, tal es el caso de la española Antena 3 con su lugar de encuentro Tercera Avenida ${ }^{6}$. Los juegos de simulación de vida real para PC o videoconsola también ayudan al usuario-jugador a crear un personaje a su medida, esta vez más limitado, en tanto que existen unas posibilidades finitas de vestuarios, escenarios, acontecimientos, sucesos y relaciones entre personajes. De ellos, sin duda, $\operatorname{los} \operatorname{Sims}^{7}$ son el fenómeno mundial por excelencia que ha generado incluso merchandising, foros, blogs, vídeos en YouTube, versiones en simlish (lengua en la que hablan los sims) ${ }^{8}$ de canciones de artistas o grupos famosos de distintos países ${ }^{9}$...

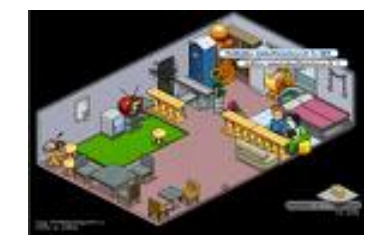

Sala del juego on line Barbiegirls

\footnotetext{
${ }^{6}$ Direcciones de todas ellas, en el mismo orden en que aparecen citadas, son: www.secondlife.com y www.secondlifespain.com, www.habbo.es y www.habbo.com, http://es.barbiegirls.com/, www.antena3tv.com/terceraavenida/ (1/IV/2008).

${ }^{7}$ Web oficial: www.lossims.com. Otras muy visitadas: www.simsmaniak.com y www.actualidadsims.com (1/IV/2008).

${ }^{8}$ Es una falsa lengua, sólo sirve para que los personajes emitan sonidos articulados que no suenen a gorjeos u otros ruidos más animales. Hasta el momento sus palabras no significan nada, pero todo se andará.

${ }^{9}$ Un ejemplo es el videoclip del grupo español La oreja de Van Gogh, que canta en la lengua simlish su tema "Dulce locura”, grupo vinculado en España a la edición de los Sims 2: http://es.youtube.com/watch?v=aEOX8x63dHs. Britney Spears ha sido ampliamente recreada en sims en diversos vídeos, muchos se pueden ver en http://es.youtube.com/results?search_query=britney+spears+sims\&search_type= $(1 / \mathrm{IV} / 2008)$.
} 
Además de estas extensiones de nuestro yo, los chats (a través de ordenador comúnmente pero cada vez más también en el teléfono móvil) nos permiten recrearnos con nicks (apodos) con los que nos conocerán los demás usuarios con los que entremos en contacto, apodos que rara vez suelen coincidir con nuestros nombres reales sino que tienden a asumir personajes de ficción, famosos o seres desconocidos o no que nos resultan atractivos o a quienes quisiéramos parecernos, por no hablar de la gran cantidad de ellos que hacen referencia a supuestas cualidades erótico-sexuales.

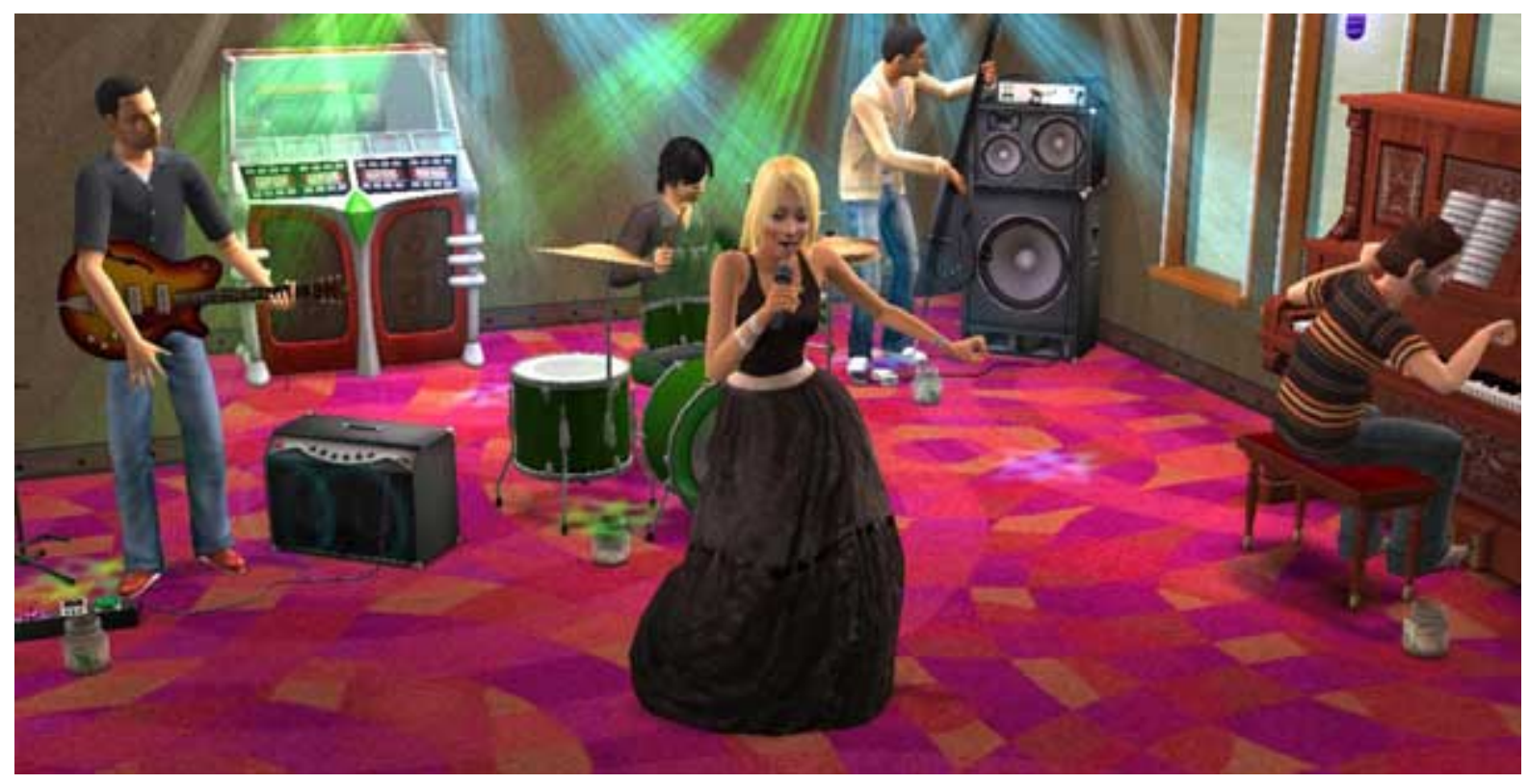

La oreja de Van Gogh en Los Sims

Desde la representación de la vida cotidiana de Goffman hasta hoy ha llovido mucho: nicks, chats, comunidades virtuales, cyborgs, cybergirls, nuevos personajes y nuevas representaciones del cuerpo, el hipocuerpo del hipertexto, un cuerpo no real pero que es una extensión de nosotros mismos, muchas veces creados como los superhombres que no podemos ser, el hipercuerpo ${ }^{\mathbf{1 0}}$. Este deseo de proyectar en la realidad nuestra imaginación llega ahora a cotas altas pero la predisposición viene de antiguo: fiestas temáticas, locales de restauración tematizados y el éxito en las últimas décadas de los parques temáticos. En todas estas experiencias simulamos algo que no somos aunque conscientes de ello. Como afirma Rosario Jiménez Morales (2007), “las masas ven en él (en

\footnotetext{
10 En palabras de Balaguer (2002), "hipocuerpo es la vivencia de pequeñez, de limitación del cuerpo, que es vivido como una herida narcisista frente a las nuevas dimensiones socioculturales del cuerpo, representadas por el hipercuerpo”.
} 
el parque temático) un País de Nunca Jamás, un lugar donde metamorfosear su cotidianeidad (...) Las áreas temáticas se conciben como secuencias, en las que la vivencia y experiencia tienen en cada una de ellas una continuidad. Ésta se transforma en paisajes aislados, micromundos que a diferencia del relato fílmico pueden ser visitados de forma aislada sin que exista una relación lineal entre ellos. Cada una de estas áreas está acompañada además de una narración, de una pequeña historia que da coherencia a los elementos arquitectónicos”. La evolución desde el lugar de espectador al de actor en este tipo de escenarios ha sido muy favorecida por las nuevas tecnologías y la no comparecencia física, lo que posibilita prescindir de escenarios, de decorados, de vestuario, peluquería y maquillaje. Esta aparición en los chats y messenger es una vuelta al fingimiento de texto, en tanto que la palabra soporta buena parte del peso de la relación entre usuarios participantes ${ }^{11}$.

Los videojuegos ${ }^{12}$ o juegos para ordenador interactivos, que son llamados incluso cine interactivo, suponen un paso intermedio entre el ser espectador de los parques temáticos y la libertad del chat. Sus guiones son establecidos a diferencia de la falta de limitación de las comunidades virtuales donde al no estar nada previsto la simulación puede ir por cualquier derrotero según cada avatar. En los juegos de rol el guión está previsto por parte del máster, pero las acciones puntuales pueden variar según los jugadores, y probablemente eso es lo más divertido para ellos, aunque el rol tiene previsto un final establecido y desarrollo de historias narrativas tradicionales de encadenamientos causales, eso sí, con posibilidades de digresiones en el relato indefinidas e irrelevantes que no suelen llevar los relatos convencionales, construyendo una narrativa episódica interactiva de interrupciones. Los juegos de ordenador o videojuegos presentan personajes máscaras, roles determinados con cierta personalidad relevante, psicológicamente endebles para favorecer la identificación con el jugador. En los de avatares la personalidad la imprime el jugador, construyendo su propio personaje aunque la apariencia física está muy constreñida por las posibilidades que ofrezca el juego en línea o no. En estos últimos el jugador no es un espectador, sino un interactor.

\footnotetext{
11 También sobre ello se ha empezado a teorizar. Así Diego Levis (2007) concluye que la comunicación digital recupera la comunicación escrita, pero mal escrita, ya que en telefonía móvil, chats, foros escribimos con nuevos códigos hasta ahora no escritos, los códigos orales. Así dice que se emplea “el habla escrita” con abreviaturas, contracciones y sacrificios vocálicos y consonánticos.

${ }^{12}$ Véase la proliferación de entusiasmos por los juegos desde el punto de vista del usuario pero también desde el del estudioso en www.gamestudies.org y www.ludology.org (10/II/2008).
} 
En la investigación realizada por Jorge Mora (2008) sobre adolescentes y videojuegos, los chicos eligen como avatares aquéllos de características étnicas parecidas a los jugadores pero se descartan avatares gordos o pequeños. Las chicas se vuelcan en buscar vestimenta para que su avatar resulte un personaje virtual sexy. Los juegos favoritos son los de violencia, deporte o acciones exploratorias, en especial los de supervivencia, ganar un premio, salvar a alguien. Es decir, todo aquello que la vida cotidiana no nos proporciona y que nos gustaría experimentar, lo que estaría en contra de lo que alguna corriente de interpretación de actores propugnaría, la proyección de la experiencia personal sobre el personaje. Entre los valores descritos durante las entrevistas con los adolescentes, los favoritos fueron la diversión, el humor, la perseverancia y la relajación, mientras que los menos señalados fueron la paciencia, el amor fraternal, la justicia y la integridad, o lo que es lo mismo: todo aquello que se enseña como valores positivos. También valoraron como atractivo en el juego el orgullo y no les interesaba la deshonestidad, la envidia, el orgullo y la crítica. Una desinhibición que parece confirmar que el ser humano cuenta con un Dr. Jekyll y un Mr. Hyde que el videojuego favorece a destapar.

El paso definitivo de coautor a actor se da con la experiencia directa en Internet, donde la simulación alcanza su nivel más alto. Las diferencias de la experiencia mediada a la directa teatral traen consecuencias que afectan especialmente al cuerpo. Los estudios del cuerpo alcanzan su categoría científica en los años 60 del siglo XX de la mano de las investigaciones sociológicas y antropológicas, en especial de los trabajos pioneros de Turner ${ }^{13}$, y su explosión se produce a finales de siglo cuando se pasa a la “visualización del cuerpo en los medios” (García Sottile, 2007). Muchas otras disciplinas se acercan a la observación del cuerpo y especialmente aquéllas que hacen de él un uso, como medio o como fin. Desde la educación, la medicina, la moda, hasta la dramaturgia, la literatura, la danza y, por supuesto el cine y la televisión. Pensar el cuerpo de los modelos, de los actores, los bailarines, de los niños no es más que desarrollar en diversos ámbitos de la actividad humana algo que ya se ha desarrollado en nuestra vida cotidiana. Desde los trabajos del ya referido Goffman sobre la representación en la vida cotidiana hasta los esfuerzos de los estudiosos en comunicación no verbal ha quedado claro que el cuerpo cumple una función que desarrolla e identifica a un yo social, que al mismo tiempo nos distingue del otro, infiriéndose de ella la distinción. La idea de cultura corporal, especificada en 1987 por Norbert Elias en El proceso de la

\footnotetext{
${ }^{13}$ Una perspectiva general puede encontrarse en el artículo de Bryan Turner “Avances recientes en la teoría del cuerpo”, en el número monográfico de la revista Reis, n68, octubre-diciembre 1994, pp.11-40.
} 
civilización (FCE, México), aglutina y trabaja sobre los gestos corporales, la vestimenta, las expresiones faciales, etc., como conformantes y desveladores de sentimientos del propietario y marcan sus relaciones con el entorno. Los esfuerzos por el control de las emociones, de comunicación no verbal encaminadas a no dejarse ver o dejarse ver en un sentido hacia los demás, confirman que de modo inconsciente todos lo sabemos. Y si es así en nuestra cotidianidad, más aún lo será en la ficción donde el cuerpo del actor es un soporte que lleva el peso de buena parte de la información de un personaje que transmite al espectador y que interviene en el relato que se pretende construir. A ello se une no sólo el uso del cuerpo en sí mismo sino el modo de construirlo y de mirarlo. Ese uso que se hace del cuerpo en los medios audiovisuales contemporáneos es síntoma de algo más que sólo eso, puede ser indicio de una cultura del cuerpo pero también de un modo aplicado de una estética cultural general de entresiglos. Si en educación el cuerpo del niño a partir de ciertas edades y en el proceso de aprendizaje conforma su conciencia de existencia, le enseña a conocer sus sentidos y sus emociones, su identidad, ese mismo proceso se ha estudiado con especial interés en el ámbito de las culturas. Como afirma De Toro (2003) ${ }^{14}$ “el cuerpo y sus partes constituyentes (sexualidad, poder, pasión, violencia, perversión, lenguaje, memoria, historia, etc.) son de fundamental y central importancia en el campo de la construcción teórica postmoderna”. En esta misma línea, queremos contribuir, junto con los escasos trabajos existentes hoy por hoy sobre el cuerpo en televisión, a ver cómo especialmente el lenguaje televisivo se ha visto contaminado de signos de nuestro tiempo y se refleja en su tratamiento del cuerpo. Y de la televisión en línea directa a la construcción que de ellos mismos hacen en Internet sobre todo los jóvenes, un cuerpo fragmentado y reconstruido.

Si la doble personalidad ha sido considerada siempre como trastorno disociativo de la identidad, como una psicopatía, o son muchos los afectados o todos tenemos una tendencia artística innata hacia la interpretación actoral. No se trata sólo de una solución para tímidos o enfermos, el fingimiento, la simulación en Internet es un hecho practicado por un alto porcentaje de usuarios del medio. La kinesia como reguladora de la conversación, se pierde en Internet, especialmente los gestos y movimientos sinceros, reacciones que pueden enmascararse a través de palabras ya pensadas, eliminando la posibilidad de desenmascarar al mentiroso. Como afirma Lorenzo García

\footnotetext{
14 “Discurso sobre la hibridez en Latinoamérica: del Descubrimiento hasta el siglo XXI”, pronunciado en el $14^{\circ}$ Congreso de la Asociación Alemana de Hispanistas, Universidad de Ratisbona, 06-09/03/2003. Disponible en línea en http://www.uni-leipzig.de/-iafsl/dhv2003/hibridez.html (17/X/2007).
} 
(2000: 39), “las señales de comunicación no verbal son más espontáneas y más difíciles de disimular que las verbales (...) Sin embargo, hay muchas personas que dominan el arte de la simulación (muchos políticos y todos los actores, son mentirosos profesionales). Si no dominamos estas técnicas, y deseamos mentir, lo aconsejable es hacerlo por teléfono o conduciendo un vehículo. Es decir, escondiendo nuestro rostro y nuestras manos”. La importancia del cuerpo y la corporeidad en el momento en que vivimos se desdobla en vertientes de degradación, desintegración del cuerpo propio al tiempo que buscamos una liberación del mismo.

En este sentido existe una corriente apocalíptica en relación al cuerpo humano y las nuevas tecnologías. "El cuerpo en nuestros días es dilacerado, tatuado y perforado, como sucede en la práctica habitual del piercing, objeto de manifestación artística y de consumo, como en el Body Art, territorio cotidiano de toda clase de modificaciones físicas y estéticas (...) y reflejo hueco de su organicidad en la duplicación digital por las nuevas tecnologías” (Domínguez y Barcellós: 2007). Las modernas tecnologías han ido desplazando al hombre progresivamente hacia una incapacidad sobre sus propias habilidades sobre las máquinas. En palabras de Esther Mera (1993:80) “el humano es sucesiva y rápidamente desposeído de unos atributos que le habían permitido percibirse a sí mismo como un ser esencialmente distinto y trascendente”. Y sobre esta base, Domínguez y Barcellós (2007) aseguran que el cuerpo se encuentra en descomposición y su pérdida de hegemonía se encuentra en las instalaciones o videoperformances de museos y bienales, que "el desarrollo de las nuevas tecnologías digitales incide aún más en el desplazamiento y la ausencia de la figura humana mediante la supresión de su organicidad”. Y también Claudia Giannetti (1995: 50) cierra esta visión negativa, aunque realista, incidiendo en la parte de culpa que tienen en ello las prácticas multimediáticas actuales: "El proceso de dramaturgia y apoteosis corporal ha seguido una vía progresiva en dirección a la fragmentación del cuerpo y su desintregración mediante el proceso digital. El ritual físico es reemplazado por el ritual tecnológico. La desmaterialización del cuerpo a través de la electrónica y de la telemática induce a un proceso de renuncia sucesiva a la presencia orgánica, que se vuelve superflua o minimizada”.

Del otro lado, la corriente integrada, basándose en el cuerpo marginado y negado de reminiscencias nietzschianas, en los cuerpos docilizados y politizados foucaultianos, en los cuerpos torcidos y raros de la Teoría Queer, entre otros referentes, reflexiona sobre el nuevo concepto del cuerpo que la era virtual puede dar a luz, un cuerpo sin cuerpo, una era de la no presencia corporal. El cuerpo puede llegar a ser considerado vestigio de una antigua era de la Humanidad alejada de la 
contemporaneidad, donde el hombre se ha liberado de su cuerpo: guantes digitales, trajes electrónicos, gafas de simulación, manipulaciones de genomas, prótesis de muchas zonas corporales, reimplantes, cirugías estéticas... En este sentido, la cibersociedad ha creado, según Planella (2007) una independencia, un neoplatonismo que crea una civilización de la mente gracias al ciberespacio, sobre la idea del platonismo que afirma que el cuerpo estorba a la mente para desarrollarse, es el lugar donde minusválidos, feos, deformes, tímidos... encuentran la libertad.

Existen posturas intermedias que nos inducen a repensar la importancia del cuerpo y la corporeidad. Meri Torras (2004) conluye:

\footnotetext{
Mutantes, monstru@s, posthuman@s, vivimos como el doble de nuestro propio cuerpo natural, ese -por imposible- obsoleto desde el principio. Siempre hemos sido cyborgs, seres y estares híbridos de humanidad y tecnologías. La facultad del lenguaje nos permite referirnos a entidades ausentes. Nuestros sentidos funcionan a modo de interfaz a través de la cual absorbemos la información del mundo. La intervención de cualquier elemento que modifique esa percepción pretendidamente natural y nos conecte con la percepción de una realidad aumentada (una hiperrealidad) deviene una tecnología que nos posthumaniza. Los límites de nuestras percepciones trazan el mapa geográfico por donde discurre nuestro conocimiento... Pero, por ahora, el cuerpo lo llevamos con nosotr@s, o nosotr@s con el cuerpo. Internet y la realidad virtual, más que la desaparición del cuerpo, suponen la obligación insoslayable de pensarlo de otro modo, el descubrimiento de que también puede ser de otro modo o, a menudo, de que siempre ha sido de otro modo (artificial, tecnológico, textual...).
}

\section{Conclusiones}

La indisolubilidad del actor y el cuerpo en la interpretación dramática empieza a plantearse. Ya no sólo existe la crisis del personaje, también la del soporte físico del personaje: decorados proyectados, seres espectrales, teatro virtual... Al igual que el teatro en televisión no es teatro, es televisión, tampoco en Internet lo es. En cualquier caso, nuestro rápido modo de habituarnos a las novedades perceptivas derivadas de las tecnologías nos llevan a no saber distinguir bien en la comunicación mediada la realidad de la ficción. Como versa el subtítulo de la revista digital Cloporto, revista sobre la ficción y la realidad, “de la ficción: todo es verdad”. En su número de 
2007 dedicado a nuevas tecnologías y teatro ${ }^{15}$ se puede ver una fotografía de un lugar de encuentro en Melbourne que parece una imagen extraída de Second Life, siendo real. Pero, ¿realmente es necesaria la toma de posición ante el ciberteatro, en cualquiera de sus sentidos? Terminamos con una inquietante pregunta que ya se hacía hace unos años el experto en teatro y cibermundo Steve Dixon (2002):

In cybernetic information and communication theory, embodiment is therefore immaterial, and according to Hayles is defined by pattern rather than presence. If this is the case, and if questions of absence and presence are not relevant to information and communication within cybernetic discourse, should they be any more relevant to digital manifestations of performance? In a postmodern age when Foucault and others have already conceptualised the body as a primarily linguistic discourse system, does the intervention of mediating technologies alter the chain of bodily information and communication production in performance?

El mejor modo de concluir es siempre plantear una nueva cuestión por donde empezar.

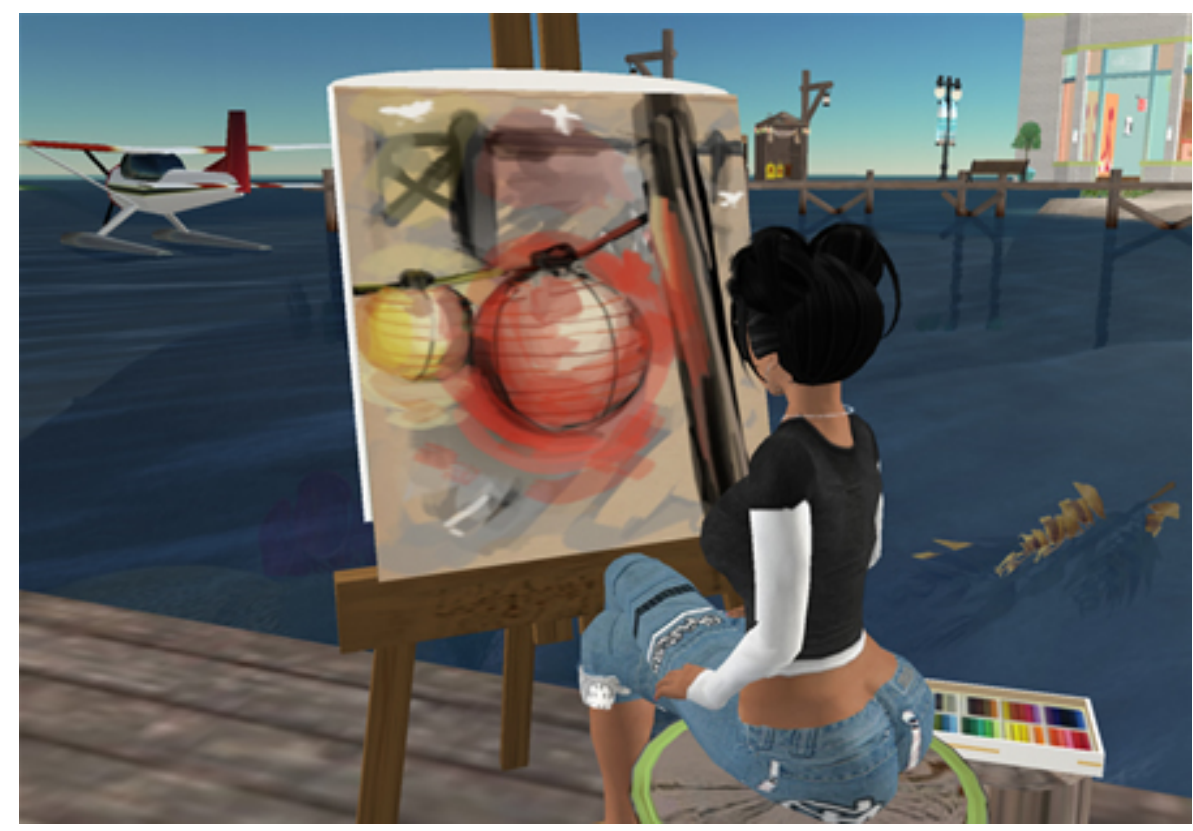

Imagen de Second Life

15 En dicha monografía se reseñan varios libros sobre el tema de fundamental importancia de Steve Dixon (Digital Performance: A History of New Media in Theater, Dance, Performance Art and Installation, y también Metal Performance Humanizing Robots, Returning to Nature, and Camping about). Véase en http://www.cloporto.com/2007/04/17/nuevas-tenologias-y-teatro-un-esnayo-historico/ (24/III/2008). 


\section{Bibliografía}

ABIRACHED, R. (1994): La crisis del personaje en el teatro moderno, Madrid, Publicaciones de la Asociación de Directores de Escena.

BALAGUER, R. (2002): “El hipocuerpo: una vivencia actual que la virtualidad aún no puede eludir”, en Revista Textos de la Cibersociedad, $\mathrm{n}^{\circ} 2$, en línea: http://www.cibersociedad.net (12/III/2008).

BOBES, C. (1987): Semiología de la obra dramática, Madrid, Taurus.

DE MARINIS, M. (2005): En busca del actor y del espectador. Comprender el teatro II, Buenos Aires, Galerna, 2005.

DIXON, S. (2002): “Internet Theatre, Posthuman Bodies and the Interctive Void”, en E-pai: Performance Arts International on-line Journal, número único anual. En línea en http://www.mdx.ac.uk/www/epai/presencesite/html/dixontol01.html (2/IV/2008).

DOMÍNGUEZ, O. y BARCELLÓS, E. (2007): “La sublimación del cuerpo en Pasolini y Almodóvar”, en Espéculo, n³6. En línea en http://www.ucm.es/info/especulo/numero36/cuerposu.html (2/IV/2008).

ECHEVERRÍA, J. (2003): “Cuerpo electrónico e identidad”, en Hernández D. (ed.): Arte, cuerpo, tecnología. Salamanca, Salamanca, Publicaciones de la Universidad de Salamanca, pp. 13-29.

GIANNETTI, Cl. (1995): “Metaformance. Proceso troposomático en la performance multimedia”, en Giannetti, Claudia (ed.): Media Culture, Barcelona, Asociación de Cultura Contemporánea L’Angelot.

HELBO, A. (1987): Teoría del espectáculo. El paradigma espectacular, Buenos Aires, Galerna HUIZINGA, J. (1951): Homo ludens, ensayo sobre la función social del juego, París, Gallimard. JIMÉNEZ MORALES, R. (2008): "Realidades ficticias: el parque temático y su relación con la industria cinematográfica”, en Área Abierta, nº 18, 2007. En línea en http://www.ucm.es/info/cavp1/Area\%20Abierta/18\%20Area\%20Abierta/investigacion.ht $\underline{\mathrm{m}}(12 / \mathrm{III} / 2008)$.

KNAPP, M.L. (1995): La comunicación no verbal. El cuerpo y el entorno, Barcelona, Paidós.

LEVIS, D. (2005): Amores en red. Relaciones afectivas en Internet, Prometeo, Buenos Aires.

LEVIS, D. (2007): “Hablar con el teclado”, en Razón y palabra, n 54, monografía sobre Comunicación y Cultura en la era digital. En línea en http://www.razonypalabra.org.mx/anteriores/n54/index.html (23/III/2008). 
LORENZO GARCÍA, J. (2000): La comunicación no verbal. Periodismo y medios audiovisuales, Madrid, Universitas.

MARTÍNEZ PORTILLO, R. y CASADO, J. (2002): Abecedario del teatro, Sevilla, Centro Andaluz de Teatro.

MERA, E. (1993): “Tecnología digital y universos descorporeizados” en Expósito, M. y Villota, G. (eds.): Plusvalías de la imagen. Rekalde, Bilbao.

MORA, J. (2008): "Expresiones hipermedia: relaciones comunicativas eficientes entre interfaz, narrativa interactiva, emociones y valores en productos lúdico-educativos”, en Comunicación, n5, monografía sobre Transmedialidad, en prensa.

PAVIS, P. (1983): Diccionario del teatro, Barcelona, Paidós.

PLANELLA, J. (2007): “Corpografías: dar la palabra al cuerpo”, en Artnodes. Revista de intersecciones entre arte, ciencia y tecnologías, $\mathrm{n}^{\circ} 6 . \quad$ En línea en http://www.uoc.edu/artnodes/6/dt/esp/planella.pdf. (1/IV/2008).

POYATOS, F. (1994): La comunicación no verbal, III. Nuevas perspectivas en novela y teatro y en su traducción, Madrid, Istmo.

SCHIMIDT, S.J. (1987): “La comunicación literaria”, en Pragmática de la comunicación literaria, J.A. Mayoral (ed.), Madrid, Arco Libros.

SIBILIA, P. (2005): El hombre postorgánico. Cuerpo, subjetividad y tecnologías digitales, Buenos Aires, F.C.E.

SITO ALBA, M. (1987): Análisis de la semiótica teatral, Madrid, UNED.

TORRAS, M. (2004): “Cuerpos, géneros, tecnologías”, en Lectora, n¹0, 2004, pp.1-4. En línea en http://www.ub.edu/cdona/lectora.htm\#10 (1/IV/2008).

TRANCÓN, S. (2006): Teoría del teatro de Santiago Trancón, Madrid, Fundamentos.

TURKLE, Sh. (1997): La vida en las pantallas. La construcción de la identidad en la era Internet, Barcelona, Paidós.

UBERSFELD, A. (1989): Semiótica teatral, Madrid, Cátedra. 